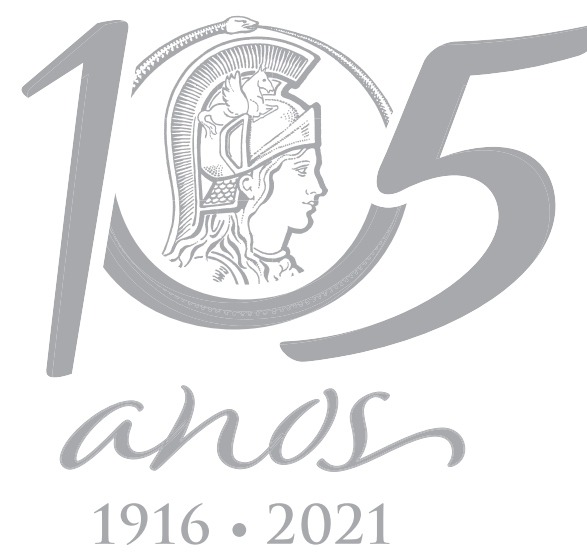

\title{
MICROBIOLOGY
}

\section{Antarctic fungi applied to textile dye bioremediation}

\author{
DANIELA M. KITA, PATRICIA GIOVANELLA, THAIIS T. YOSHINAGA, ELISA P. \\ PELLIZZER \& LARA D. SETTE
}

\begin{abstract}
Antarctica has one of the most hostile conditions on the planet. The environmental characteristics found in this region favor the development of extremophile microorganisms, which are poorly explored biotechnologically. In this context, this study aimed at selectively isolating fungi with potential for the bioremediation of a textile dye. A total of 11 filamentous fungi were isolated from Antarctic samples after incubation in Minimal Mineral medium with the addition of Sulphur Indigo Blue dye. The Antarctic-derived fungi were submitted to textile dye decolorization analysis and biomass production. Isolates LAMAI 2400 and LAMAI 2402 showed more than 90\% of decolorization at $15{ }^{\circ} \mathrm{C}$, whereas at $28{ }^{\circ} \mathrm{C}$ these isolates showed 81.86 and $98.89 \%$, respectively. In general, the toxicity of the bioassays, evaluated using Cucumis sativus, was higher than in the control. Both isolates, LAMAI 2400 and LAMAI 2402, were identified as Penicillium cf. oxalicum and classified as mesophilic-psychrotolerant. This fungal species has rarely been reported in the Antarctic environments. The results presented herein indicate the potential of the fungi recovered from Antarctic marine sediments for bioremediation of textile dyes at low and moderate temperatures, broadening the perspectives in the field of Antarctic mycology.
\end{abstract}

Key words: Antarctica, environmental biotechnology, extremophiles, mycology, pollutants.

\section{INTRODUCTION}

The Antarctic environment presents hostile conditions, being characterized by low temperatures, high incidence of radiation (mainly UV), high salinity, frequent freeze-thaw cycles, dryness, low nutrient content and long periods of darkness (Onofri et al. 2007, D'elia et al. 2009, Yergeau \& Kowalchuk 2008). All these factors hinder the development of many forms of life (Wilkins et al. 2013), and the survival in such extreme conditions requires adaptations (Margesin et al. 2002, Duarte et al. 2018a). Nevertheless, there is evidence that Antarctica is a reservoir of microbial diversity, where new species, genes, and biochemical pathways with biotechnological applications can be found (Varrella et al. 2021).

Microbial life in Antarctica has a key role in nutrient recycling, providing the basis for the function of marine and terrestrial environments (Onofri et al. 2007, Ruisi et al. 2007). The fungi that inhabit marine sediments and soil are dominant components of the biomass in Antarctic ecosystems (Wynn-Williams 1996) and can be classified as psychrophilic, psychrotolerant (psychrotrophic), and mesophilic-psychrotolerant. The first includes microorganisms able of growing at $0{ }^{\circ} \mathrm{C}$, with optimum growth at temperatures $\leq 15^{\circ} \mathrm{C}$ and maximum growth at temperatures $\leq 20{ }^{\circ} \mathrm{C}$. The second includes microorganisms that can grow 
at $0{ }^{\circ} \mathrm{C}$, but with maximum growth temperature between 15 and $25{ }^{\circ} \mathrm{C}$. The third includes microorganisms that have the ability to grow at low temperatures, with optimum growth at temperatures $>25^{\circ} \mathrm{C}$ and $\leq 40{ }^{\circ} \mathrm{C}$ (Ruisi et al. 2007, Pesciaroli et al. 2012). The production of cold-adapted enzymes, exopolysaccharides, antifreeze proteins, photoprotective pigments and cryoprotective carbohydrates are some of the important adaptations for fungal survival in harsh ecosystems like Antarctica (Krishnan et al. 2011, Duarte et al. 2018a).

According to Selbmann (2019), extremophile fungi can exhibit exceptional resistance to stress, with resistance mechanisms not only related to their natural environment. Fungal strains isolated from Antarctic environments are able to produce hydrolytic and oxidative (oxidoreductases) enzymes at low/moderate temperatures (Duarte et al. 2018a). Among oxidoreductases, the ligninolytic enzymes MnP, LiP and laccase stand out, which can be used to decolorize a wide range of industrial dyes due to the structural similarity of these compounds to lignin (Chauhan \& Choudhury 2021).

The significant quantities of textile dye that are discharged into effluents modify the whole ecosystem, impeding light penetration into water and, consequently, reducing photosynthesis rates and inhibiting the growth of aquatic biota (Enayatzamir et al. 2009, Hossain et al. 2018). Furthermore, these pollutants can cause damage to the human body because of their toxic properties, even increasing the risks of developing some diseases, like cancer (Chung et al. 1992, Chequer et al. 2011). Considering this, currently, there has been interest in the exploration of fungi for dye decolorization and degradation (Mostafa et al. 2019). Pramanik \& Chaudhuri (2018) studied the decolorization of Rose Bengal dye by the fungus Podoscypha elegans, obtaining $70.4 \%$ of decolorization. A study performed by Ortiz-Monsalve et al. (2019) using dye-containing wastewaters resulted in $90 \%$ of color removal using the fungus Trametes villosa SCS-10. Additionally, Ameen et al. (2016) reported the ability of four Aspergillus species (A. flavus, A. fumigatus, A. niger and A. terreus) to degrade the azo dyes Acid Blue 29, Disperse Red 1 and Congo Red, in a synthetic wastewater. Although textile dye decolorization and degradation are of utmost relevance, toxic intermediates can be formed during the biodegradation process (Sen et al. 2016). Since the biodegradation of dyes depends on the fungal species, strain, dye molecule, culture medium and environmental conditions, the degradation products (metabolites) may differ (Mostafa et al. 2019). In this sense, the assessment of growth medium toxicity resulting from dye degradation is relevant for the formulation of bioremediation strategies (Giovanella et al. 2020, Vieira et al. 2021). Despite the relevance of the fungal metabolic arsenal for dye decolorization and detoxification, studies that use Antarcticderived fungi for the bioremediation of textile dyes are still scarce.

The importance of filamentous fungi for textile dye decolorization and the lack of information on the potential of Antarcticderived fungi for the bioremediation of this kind of environmental pollutant motivated the performance of this study. In this context, the enrichment strategy for the selective isolation of fungi from marine and terrestrial Antarctic samples was applied. The isolated strains were analyzed for the potential of Sulphur Indigo Blue textile dye decolorization and biomass production. The selected strains were evaluated regarding their dye detoxification potential and were taxonomically characterized. An effort was made in this study to broaden the innovation of Antarctic microbial research. 


\section{MATERIALS AND METHODS}

\section{Sampling sites}

Soil and marine sediment samples were collected from two different Islands in the Antarctic Peninsula (Figure 1) during the XXXVII Brazilian Antarctic Operation (OPERANTAR) in December 2018 (Process number 02000.005323/201852 authorized by the Brazilian Environmental Assessment Group - GAAm/PROANTAR on July $2^{\text {nd }}, 2018$ ). At Botany and Hennequin Points, superficial soil was collected, while at Comandante Ferraz Brazilian Station EACF Helipad (King George Island) and Whalers Bay (Deception Island), marine sediments were collected using a box-corer. Three simple samples were collected from each point using sterilized tools, stored in sterile "Whirl-Pak" bags (Nasco, United States), and maintained at $7{ }^{\circ} \mathrm{C}$ during transportation, until the arrival at the laboratory in Brazil, where they were also maintained at $7{ }^{\circ} \mathrm{C}$. Only one sample from each point was used for the enrichment procedure.

\section{Isolation of filamentous fungi from soil and marine sediment}

For fungal isolation, the enrichment technique was conducted as described by Spini et al. (2018), with modifications. In this process, $5 \mathrm{~g}$ of samples were added into an Erlenmeyer flask containing $50 \mathrm{~mL}$ of Minimum Mineral medium (In g L ${ }^{-1}$ : 0.7 $\left.\mathrm{KCl}, 2.5 \mathrm{NaH}_{2} \mathrm{PO}_{4}, 3.0 \mathrm{Na}_{2} \mathrm{HPO}_{4}, 1.0\left(\mathrm{NH}_{4}\right)_{2} \mathrm{SO}_{4}\right), 1$ $\mathrm{mL}$ of micronutrient solution (In g L': $4 \mathrm{MgSO}_{4}$. $0.2 \mathrm{FeSO}_{4}, 0.2 \mathrm{MnCl}_{2}, 0.2 \mathrm{CaCl}_{2}$ ), supplemented with $150 \mathrm{mg} \mathrm{L}^{-1}$ of chloramphenicol and $400 \mathrm{mg}$
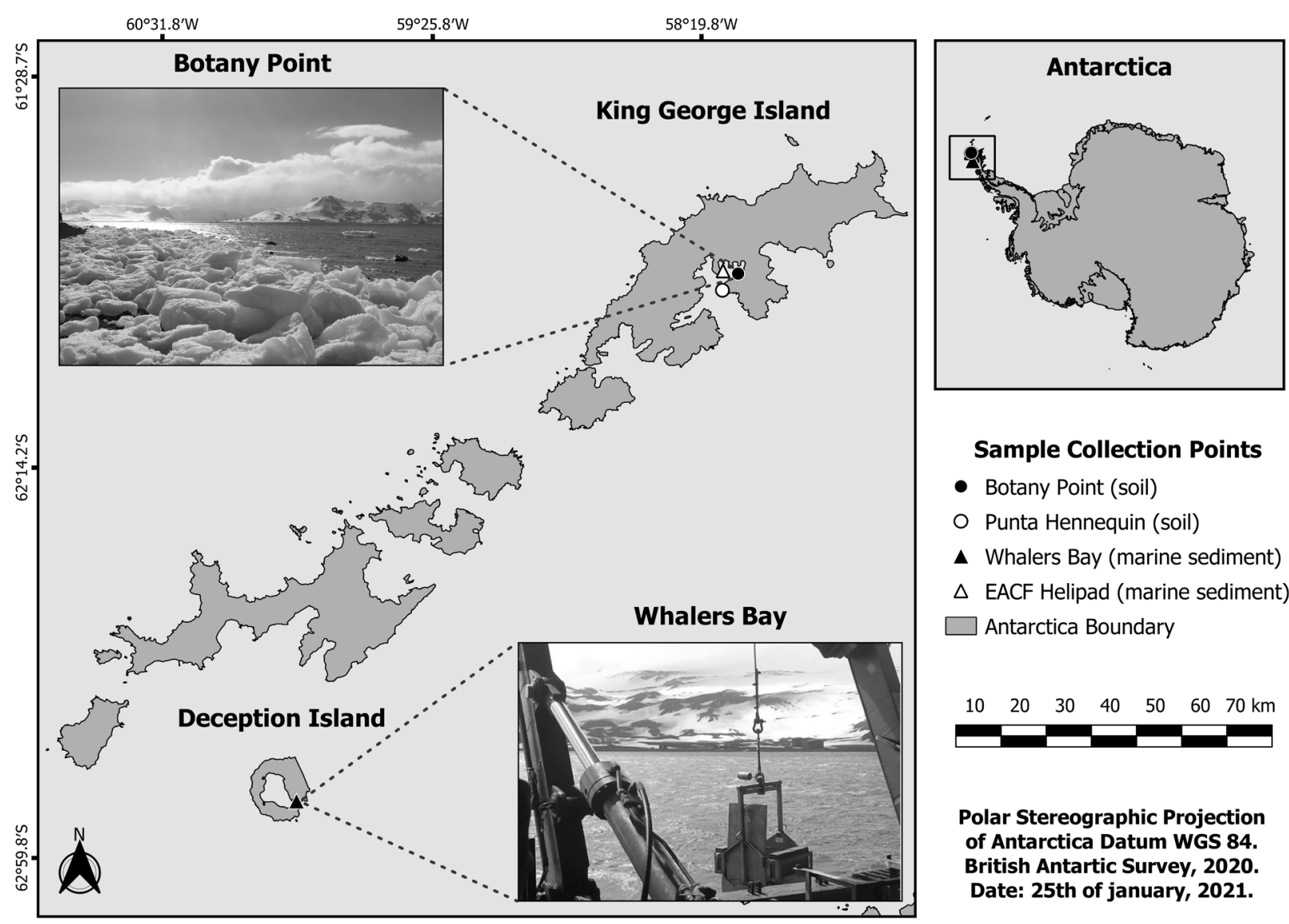

\section{Sample Collection Points}

- Botany Point (soil)

- Punta Hennequin (soil)

A Whalers Bay (marine sediment)

$\triangle$ EACF Helipad (marine sediment)

$\square$ Antarctica Boundary

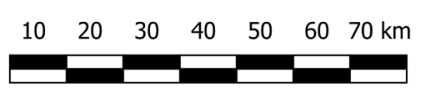

Polar Stereographic Projection of Antarctica Datum WGS 84. British Antartic Survey, 2020. Date: 25th of january, 2021.

Figure 1. Sampling sites in King George Island (Admiralty Bay) and Deception Island (Whalers Bay), South Shetlands Archipelago, Maritime Antarctica. 
$\mathrm{L}^{-1}$ of Sulphur Indigo Blue dye. Subsequently, the Erlenmeyer flasks were refrigerated at $15{ }^{\circ} \mathrm{C}$ with agitation at $140 \mathrm{rpm}$ for 15 days. After this period, $5 \mathrm{~mL}$ of the microbial culture were transferred to another Erlenmeyer flask containing the same medium described above and incubated under the same conditions for additional 15 days. At the end of three transfers, $100 \mu \mathrm{L}$ of the culture was removed to make dilutions up to $10^{-4}$, which were used for the inoculation

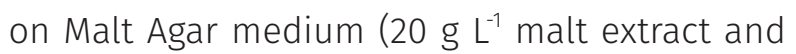
$20 \mathrm{~g} \mathrm{~L}^{-1}$ agar) supplemented with $150 \mathrm{mg} \mathrm{L}^{-1}$ of chloramphenicol. The plates were incubated at $15^{\circ} \mathrm{C}$ until the appearance of colonies, which were isolated according to the morphological differences and purified for later experiments.

Fungal isolates were preserved by two distinct methods: cryopreservation $\left(-80^{\circ} \mathrm{C}\right)$ and Castellani $\left(4^{\circ} \mathrm{C}\right)$, using cryotubes with $10 \%$ glycerol and water, respectively. All fungal isolates were deposited in the Microbial Resource Center Culture Collection (CRM-UNESP) of the São Paulo State University, Rio Claro, Brazil.

\section{Decolorization and detoxification of Sulphur Indigo Blue textile dye}

The cultivation of the filamentous fungi was performed as described by Vieira et al. (2021), with modifications. All isolates were cultivated on Petri dishes containing Malt Agar medium and $150 \mathrm{mg} \mathrm{L}^{-1}$ of chloramphenicol for 7 days at $15^{\circ} \mathrm{C}$ or $28^{\circ} \mathrm{C}$. Subsequently, three culture discs ( $5 \mathrm{~mm}$ in diameter) from the edge of the colony were aseptically transferred to an Erlenmeyer flask containing $50 \mathrm{~mL}$ of Malt Broth medium (20 $\mathrm{g} \mathrm{L}^{-1}$ of malt extract) supplemented with Sulphur Indigo Blue textile dye $\left(400 \mathrm{mg} \mathrm{L}^{-1}\right)$ and incubated for 7 days at $15{ }^{\circ} \mathrm{C}$ or $28^{\circ} \mathrm{C}$ and 140 $\mathrm{rpm}$. All assays were conducted in triplicate.

\section{Dry biomass}

For the measurement of the dry biomass, the procedures reported by (Vieira et al. 2021) were applied. Cultures of filamentous fungi were filtered in qualitative filter paper (previously dried) to separate the fungal biomass from the supernatant. The fungal biomass was dried at $105^{\circ} \mathrm{C}$ and measured after $24 \mathrm{~h}$. The difference between the final mass (dry mycelium + filter paper) and initial mass (filter paper) was the fungal biomass value. The same procedure was performed in the control group containing the culture medium and the Sulphur Indigo Blue textile dye.

\section{Decolorization assay}

To evaluate decolorization, the supernatants were diluted in water (5:5) and evaluated on a UV-Vis spectrophotometer (Shimadzu UV-1240, Kyoto, Japan), according to Bonugli-Santos et al. (2012). The decolorizing activity was calculated from the maximum absorption peak $(600 \mathrm{~nm})$ of the dye, according to the following formula:

$$
\text { Decolorization }(\%)=\frac{\text { Initialabsorbance }- \text { Finalabsorbance }}{\text { Initialabsorbance }} \times 100
$$

\section{Detoxification assay}

Phytotoxicity assessment using Cucumis sativus was conducted in Petri dishes based on the study performed by Wang et al. (2001), with modifications. Each Petri dish containing 15 seeds without pesticides and $5 \mathrm{~mL}$ of the supernatant (adjusted to $\mathrm{pH}$ 7.0) placed on a filter paper was individually wrapped with plastic film to prevent water evaporation, and incubated at $24^{\circ} \mathrm{C}$ in the dark, for 5 days. The negative control consisted in a solution of $0.05 \mathrm{M} \mathrm{ZnSO}_{4}$ and the positive control was distilled water. At the end of the experiment, the hypocotyl and root of each seed were measured. Only the seeds with 
growth of $5 \mathrm{~mm}$ or more were considered. The calculation of hypocotyl + root growth inhibition was performed using the following equation:

Inhibition $(\%)=\frac{\text { Mean of the positive control }- \text { Mean of the bioassay }}{\text { Mean of the positive control }} \times 100$

\section{Fungal identification and classification}

The best-performing fungi in the decolorization experiment (80\% or more of dye decolorization) were selected for taxonomic identification and classification (based on their growth temperature). For molecular taxonomy, the DNA from the Antarctic fungi was extracted following the method described by Lacerda et al. (2018). The internal transcribed spacer (ITS1-5.8S-ITS2) was amplified according to Santos et al. (2020) using the universal primers ITS4 (5'TCCTCCGCTTATTGATATGC3') and ITS5 (5'GGAAGTAAAAGTCGTAACAAGG3'). The amplicons were purified using the enzymes Exonuclease I and alkaline phosphatase (Thermo Scientific, Waltham, MA, USA) according to the manufacturer's protocol. The samples were quantified in NanoDrop (Thermo Scientific, MA, USA) and sequenced by a specialized company using the Sanger sequencing method. The generated sequences were processed (trimmed tails and quality Phred checking) using BioEdit v.7.2.5 (Hall 1999) and assembled into contigs using CAP3 (Huang \& Madan 1999). All sequences were compared with GenBank and CBS Fungal Biodiversity Centre sequences using BLAST (Altschul et al. 1990), and alignments were performed using MUSCLE (Edgar 2004) in the MEGA X version 10.2.6 package (Kumar et al. 2018). Evolutionary distances were calculated using the Maximum Likelihood algorithm and Kimura-2p nucleotide substitution model (Kimura 1980), which takes into account differences in transitions and transversions. The robustness of the trees was calculated using the bootstrap method, with 1000 generations. The tree was produced using the iTOL web application (Letunic \& Bork 2021). The ITS sequences of the selected fungal strains were deposited in GenBank under the following accession numbers: MZ376947 and MZ376948. For the morphological characterization, the fungi were cultivated in Malt Agar blocks under a cover glass to obtain the reproductive structures for further investigation. The system was incubated at $15{ }^{\circ} \mathrm{C}$ until sporulation. After sporulation, the cover glass was transferred to a slant with a drop of cotton blue and then observed under light microscopy.

To define growth temperature range, a spore suspension $\left(1 \times 10^{6}\right)$ was prepared and $10 \mu \mathrm{L}$ were inoculated in Malt Agar medium for 7 days at four different temperatures: 15, 20, 25 and $30{ }^{\circ} \mathrm{C}$. After the incubation period, the plates were photo-documented, and the growth area $\left(\mathrm{cm}^{2}\right)$ was measured using the software ImageJ (Abramoff et al. 2004).

\section{Statistical analysis}

The data obtained were analyzed by XLSTAT 2020. The normality of the data was checked for each treatment (Ryan-Joyner test with $p$-value >0.05). For parametric distributions, the data were compared using ANOVA followed by the Tukey's test ( $p$-value of 0.05 ). For non-parametric distributions, the data were compared using the Kruskal Wallis test followed by the ConoverIman's post-hoc test.

\section{RESULTS}

\section{Isolation of filamentous fungi from soils and marine sediments}

A total of 29 microorganisms were isolated and purified from Antarctic soil and marine sediment samples after 45 days of enrichment with Sulphur Indigo Blue dye. Among them, 11 
were characterized as filamentous fungi based on morphological features. A higher number of filamentous fungi were recovered from marine sediment samples $(n=9)$ compared to soil samples $(n=2)$ (Table I). From the marine sediment samples, 5 isolates were recovered from the sample collected in Whalers Bay (Deception Island) and 4 from the sample collected in EACF Helipad (King George Island). From the soil samples, 1 isolate was recovered from the soil collected in Punta Hennequin and the other, from the soil collected in Botany Point, both placed at King George Island.

\section{Decolorization and detoxification of Sulphur Indigo Blue textile dye}

Selectively isolated filamentous fungi were able to decolorize the textile dye Sulphur Indigo Blue at $15{ }^{\circ} \mathrm{C}$ and the decolorization rates varied from $0.64 \%$ to $94.88 \%$ (Figure $2 \mathrm{a}$ ). In the experiments performed at $28{ }^{\circ} \mathrm{C}$, the percentage of decolorization varied from $0.35 \%$ to $98.89 \%$ (Figure 2b). At this temperature, two isolates (LAMAI 2399 and LAMAI 2423) did not show dye decolorization.

In general, the filamentous fungi presented similar decolorization rates at 15 and $28{ }^{\circ} \mathrm{C}$. Isolates LAMAI 2400 and LAMAI 2402 stood out as the best decolorizers at both temperatures (Figure $2 \mathrm{a}, \mathrm{b}$ ) with more than $93 \%$ of dye decolorization at $15{ }^{\circ} \mathrm{C}$, and $81.86 \%$ (LAMAl 2400) and $98.89 \%$ (LAMAI 2402) at $28^{\circ} \mathrm{C}$. Both of them were recovered from the marine sediment collected in Deception Island. Isolates LAMAI 2398, LAMAI 2399, LAMAI 2401, LAMAI 2410, LAMAI 2422 and LAMAI 2423 were able to decolorize the dye at rates above $20 \%$ at both temperatures. Isolates LAMAI 2424 and LAMAI 2425 showed a lower capacity to decolorize the dye at $15^{\circ} \mathrm{C}$ (less than $10 \%$ ) than at $28{ }^{\circ} \mathrm{C}$ (more than $40 \%$ ).

There was less variation in the biomass produced by the Antarctic filamentous fungi in the bioassays conducted at $15{ }^{\circ} \mathrm{C}$ (Figure 3a) in comparison with the bioassays performed at $28{ }^{\circ} \mathrm{C}$ (Figure 3b). The biomass at $15{ }^{\circ} \mathrm{C}$ varied between $0.506 \mathrm{~g} \mathrm{~L}^{-1}$ and $0.859 \mathrm{~g} \mathrm{~L}^{-1}$, while at $28^{\circ} \mathrm{C}$, biomass variation was between $0.162 \mathrm{~g} \mathrm{~L}^{-1}$ and $0.959 \mathrm{~g} \mathrm{~L}^{-1}$ (Figure 3a). The fungal isolate LAMAI 2400 produced the highest amount of biomass at $15^{\circ} \mathrm{C}$, whereas the isolate LAMAI 2425 showed the best biomass production at $28^{\circ} \mathrm{C}$ (Figure $3 \mathrm{~b}$ ).

Isolates LAMAI 2399 and LAMAI 2423, which did not show dye decolorization at $28{ }^{\circ} \mathrm{C}$ (Figure $2 b)$, were not able to produce biomass at this temperature (Figure 3b). Nonetheless, at $15{ }^{\circ} \mathrm{C}$, the biomass produced was $0.663 \mathrm{~g} \mathrm{~L}^{-1}$ (LAMAI 2399) and $0.816 \mathrm{~g} \mathrm{~L}^{-1}$ (LAMAI 2423) (Figure 3a). It was not possible to establish a direct relationship between the amount of biomass produced and the Sulphur Indigo Blue decolorization rates. Nevertheless, for the best decolorizers (LAMAI 2400 and 2402), the amount of biomass produced was among the highest at both temperatures.

Based on the results of decolorization and biomass production, isolates LAMAI 2400 and LAMAI 2402 were selected and the bioassays conducted with these isolates were submitted to the toxicity analyses using $C$. sativus as bioindicator.

The results at $15^{\circ} \mathrm{C}$ showed that the toxicity of the bioassay performed with the selected isolates was higher than the toxicity of the control, composed of Malt Broth medium with Sulphur Indigo Blue textile dye (Figure 4a). LAMAI 2400 and LAMAI 2402 showed 83.44 and $83.07 \%$ of C. sativus hypocotyl + root inhibition, respectively, while in the control the inhibition was $27.64 \%$. However, at $28{ }^{\circ} \mathrm{C}$ (Figure $4 \mathrm{~b}$ ), the bioassay performed with the isolate LAMAI 2400 showed toxicity $(41.16 \%)$ at the same level as the control (46.16\%). At this temperature, the toxicity in the bioassay with the isolate LAMAI 2402 (73.41\%) was also higher than the toxicity of the control. 
Table I. Data on the soils and marine sediments collected at Maritime Antarctica during OPERANTAR XXXVII (December 2018) and fungal strains isolated from these samples.

\begin{tabular}{|c|c|c|c|c|c|c|}
\hline Site & $\begin{array}{l}\text { Geographic } \\
\text { coordinates }\end{array}$ & Depth (m) & $\begin{array}{c}\text { Average } \\
\mathrm{T}\left({ }^{\circ} \mathrm{C}\right)\end{array}$ & Sample & $\begin{array}{l}\text { Filamentous } \\
\text { fungi }\end{array}$ & LAMAI code \\
\hline \multirow{5}{*}{$\begin{array}{c}\text { Deception Island Whalers } \\
\text { bay } \\
\text { (SMWB1) }\end{array}$} & \multirow{5}{*}{$\begin{array}{l}62^{\circ} 59.071^{\prime} \mathrm{S} \\
60^{\circ} 33.720^{\circ} \mathrm{W}\end{array}$} & \multirow{5}{*}{95.4} & \multirow{5}{*}{$N D^{*}$} & \multirow{5}{*}{$\begin{array}{l}\text { Marine } \\
\text { sediment }\end{array}$} & D2A & LAMAI 2398 \\
\hline & & & & & D2B & LAMAI 2399 \\
\hline & & & & & $\mathrm{D} 2 \mathrm{C}$ & LAMAI 2400 \\
\hline & & & & & D2D & LAMAI 2401 \\
\hline & & & & & $\mathrm{D} 2 \mathrm{P}$ & LAMAI 2402 \\
\hline \multirow{4}{*}{$\begin{array}{l}\text { King George Island } \\
\text { EACF Helipad } \\
\text { (SMEACF1) }\end{array}$} & \multirow{4}{*}{$\begin{array}{c}62^{\circ} 05.168^{\prime} \mathrm{S} \\
58^{\circ} 22.829^{\prime} \mathrm{W}\end{array}$} & \multirow{4}{*}{60.0} & \multirow{4}{*}{$N D^{*}$} & \multirow{4}{*}{$\begin{array}{l}\text { Marine } \\
\text { sediment }\end{array}$} & D8A & LAMAI 2422 \\
\hline & & & & & D8B & LAMAI 2423 \\
\hline & & & & & D8C1 & LAMAI 2424 \\
\hline & & & & & D8C2 & LAMAI 2425 \\
\hline $\begin{array}{l}\text { King George Island } \\
\text { Punta Hennequin } \\
(\mathrm{SOH} 2)\end{array}$ & $\begin{array}{l}62^{\circ} 07.429^{\circ} \mathrm{S} \\
58^{\circ} 23.697^{\circ} \mathrm{W}\end{array}$ & $\begin{array}{c}\text { Superficial } \\
(0.5 \mathrm{~cm})\end{array}$ & 6.9 & Soil & D3D & LAMAI 2406 \\
\hline $\begin{array}{c}\text { King George Island Botany } \\
\text { point } \\
\text { (SOBP1) }\end{array}$ & $\begin{array}{l}62^{\circ} 05.744^{\prime} \mathrm{S} \\
58^{\circ} 19.145^{\circ} \mathrm{W}\end{array}$ & $\begin{array}{l}\text { Superficial } \\
(0.5 \mathrm{~cm})\end{array}$ & 7.3 & Soil & D4C & LAMAI 2410 \\
\hline
\end{tabular}

*ND $=$ Not Determined.
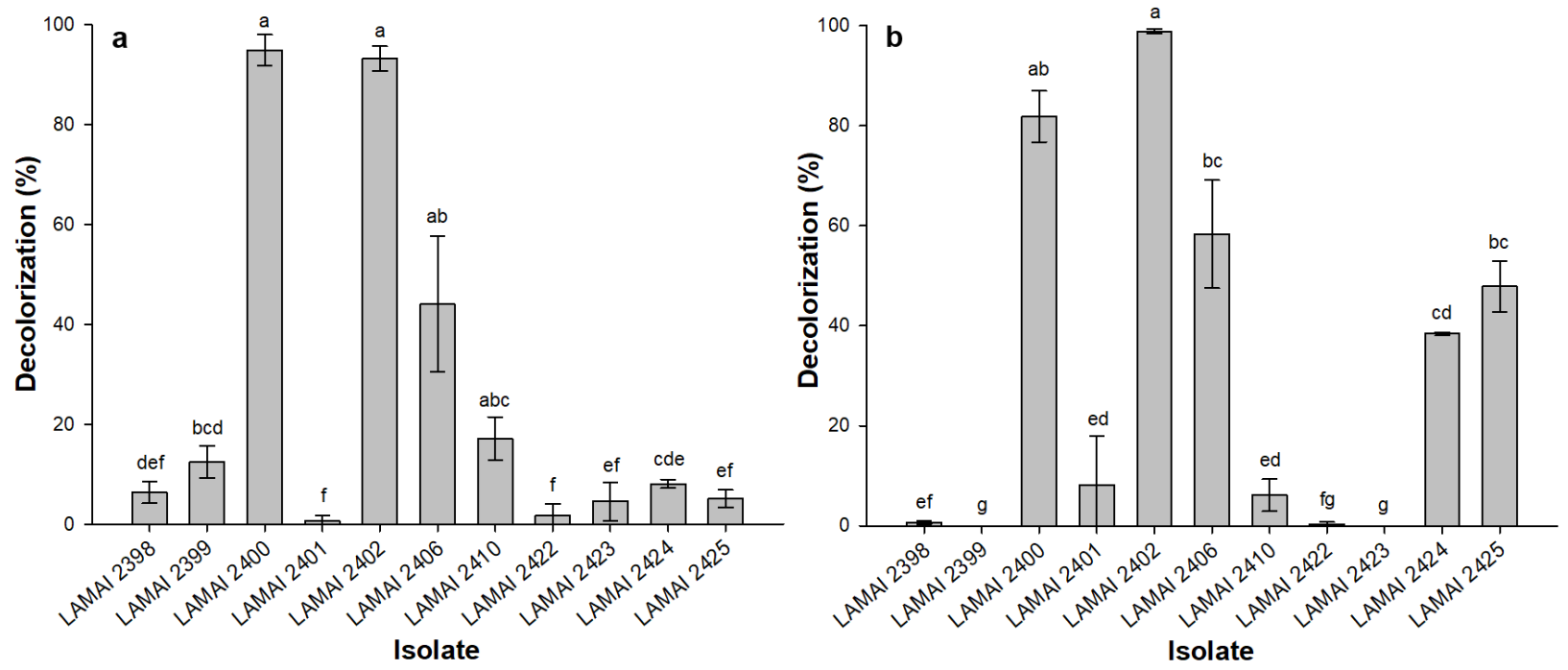

Figure 2. Percentage of Sulphur Indigo Blue decolorization by Antarctic filamentous fungi after 7 days of cultivation in Malt Broth medium containing $400 \mathrm{~g} \mathrm{~L}^{-1}$ of the textile dye. a) Incubation at $15^{\circ} \mathrm{C}$ and $140 \mathrm{rpm}$ and b) Incubation at $28^{\circ} \mathrm{C}$ and $140 \mathrm{rpm}$. Values indicated by different letters are significantly different according to the ConoverIman's test $(p<0.05)$. The vertical lines represent the standard error. 

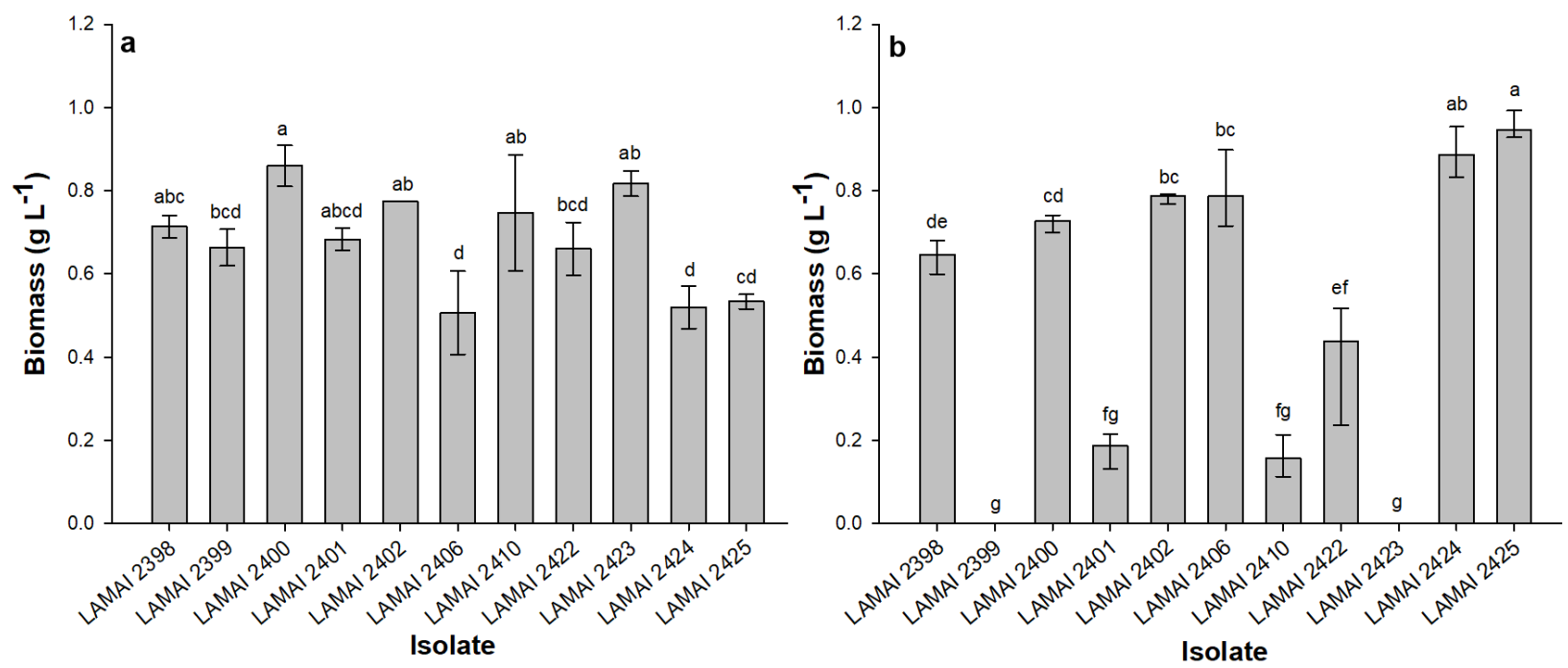

Figure 3. Dry biomass of the Antarctic filamentous fungi after 7 days of cultivation in Malt Broth medium containing $400 \mathrm{~g} \mathrm{~L}^{-1}$ of the textile dye. a) Incubation at $15^{\circ} \mathrm{C}$ and $140 \mathrm{rpm}$ - Values indicated by different letters are significantly different according to the Tukey's test $(p<0.05)$ and $b$ ) Incubation at $28^{\circ} \mathrm{C}$ and $140 \mathrm{rpm}$. Values indicated by different letters are significantly different according to the Conover-Iman's test $(p<0.05)$. The vertical lines represent the standard error.
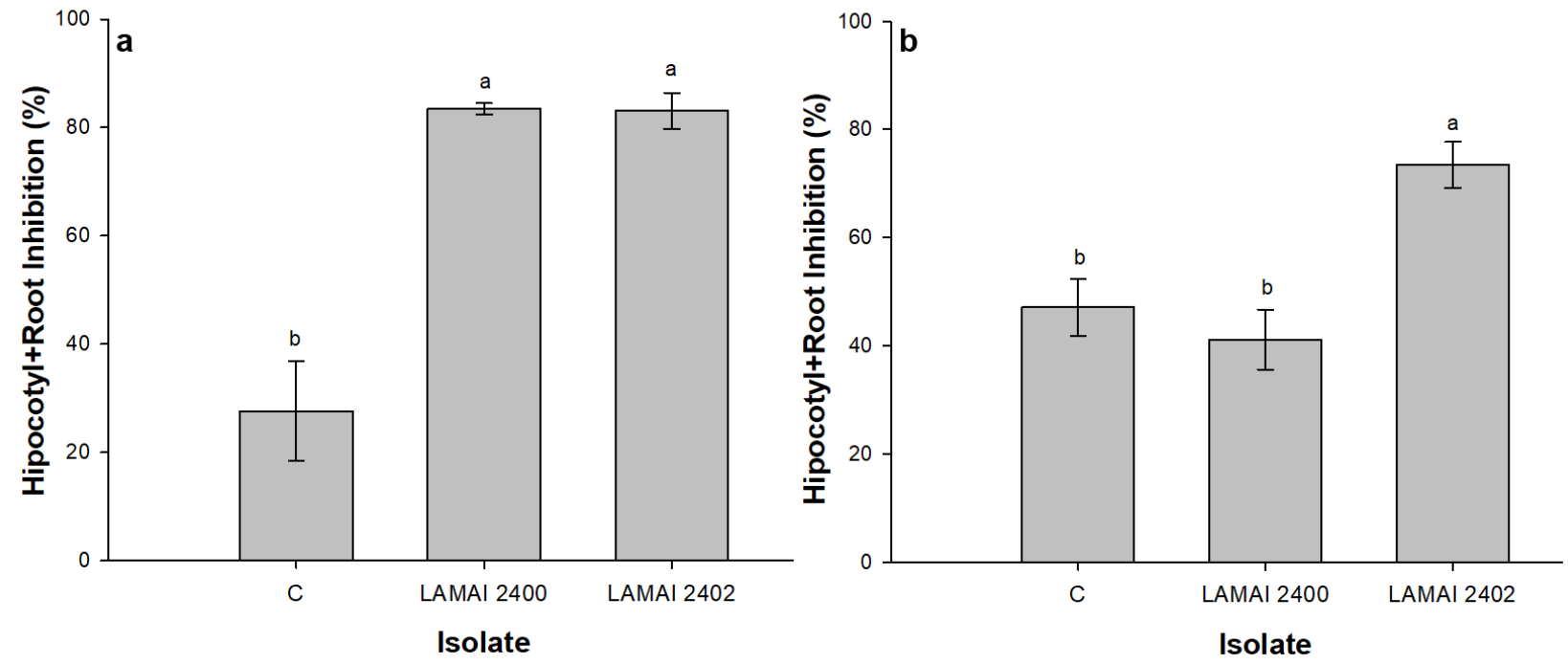

Figure 4. Toxicity of the bioassays performed with the Antarctic filamentous fungi that showed more than $80 \%$ of decolorization using $C$. sativus as bioindicator. a) Incubated at $15^{\circ} \mathrm{C}$ and b) Incubated at $28{ }^{\circ} \mathrm{C}$. Values indicated by different letters are significantly different according to the Tukey's test $(p<0.05)$. The vertical lines represent the standard error.

\section{Identification and classification of the selected fungi}

The ITS sequence (DNA barcode for fungi) of the selected Antarctic-derived fungi LAMAI 2400 and LAMAI 2402 showed 99\% of similarity with the type (CBS 219.30') and neotype (NRRL $787^{\mathrm{NT}}$ ) strains of Penicillium oxalicum, and with the type strain of Penicillium asturianum CBS $173.81^{\top}$ (current P. oxalicum). Additionally, the sequences of the Antarctic fungi were $98 \%$ similar to the type strains of Penicillium soosanum. 
Sequence similarity with type strains of other Penicillium species was less than $96.80 \%$. In the phylogenetic tree, the sequences of both fungi (LAMAI 2400 and LAMAI 20402) grouped in a cluster composed only of sequences of P. oxalicum isolates, with a bootstrap value of 95\% (Figure 5), indicating that these isolates belong to the group of P. oxalicum. Macro and micromorphological features after the growth of both fungi on malt extract agar were similar to the characteristics of $P$. oxalicum reported by Kubátová et al. (2019). Culture characteristics include submerged marginal hyphae; velutinous texture; light green to dark yellowish green conidia en masse; absent exudate and soluble pigment; pale reverse (data not shown). The asexual state (micromorphology) includes terminally branched conidiophores, typically bi-verticillate or monoverticillate, cylindrical phialides and ellipsoidal conidia (data not shown). These results allow the identification of the Antarctic-derived fungi as Penicillim cf. oxalicum.
The Antarctic fungi Penicillium cf. oxalicum LAMAI 2400 and LAMAI 2402 were able to grow at all temperatures tested (from 15 to $30^{\circ} \mathrm{C}$ ) as shown in Table II. The growth area increased with the rise in temperature and the best growth was achieved at $25-30{ }^{\circ} \mathrm{C}$ for strain LAMAI 2400 and $30{ }^{\circ} \mathrm{C}$ for strain LAMAI 2402. This behavior is characteristic of mesophilic-psychrotolerant microorganisms.

\section{DISCUSSION}

\section{Isolation of filamentous fungi from soils and marine sediments}

The enrichment strategy applied in this study allowed the isolation of 11 potentially textile dyedegrading filamentous fungi from marine and terrestrial samples collected during OPERANTAR XXXVII (December 2018). All of them showed some Sulphur Indigo Blue dye decolorization at 15 and $28{ }^{\circ} \mathrm{C}$, with the exception of two isolates that were not able to grow at $28{ }^{\circ} \mathrm{C}$. According to Pham \& Kim (2012), this methodology

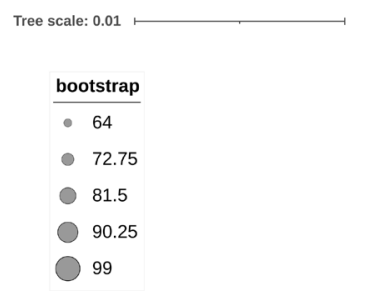

Penicillium diatomitis CCF 3779 (HE651147)

Penicillium diatomitis CCF 3780 (HE651148)

Penicillium diatomitis MH110 (HE651151)

Penicillium diatomitis CCF 3904 T (FJ430748)

Penicillium soosanum CCF 3778 T (FJ430745)

Penicillium soosanum CCF 3776 T (LT797554)

Penicillium soosanum MH729 (FJ430746)

Penicillium oxalicum NRRL $787 T$ (NR121232)

Penicillium oxalicum CBS 219.30NT (MH855125)

Penicillium oxalicum CBS 173.81T (type of $P$. asturianum) (MH861321)

Penicillium oxalicum CCF 1677 (HE651145)

Penicillium oxalicum CCF 1959 (HE651144)

- Penicillium cf. oxalicum LAMAI 2400 (MZ376947)

Penicillium cf. oxalicum LAMAI 2402 (MZ376948)

Penicillium oxalicum CCF 3438 (HE651143)

Penicillium oxalicum CCF 3009 (HE651142)

Penicillium tanzanicum CBS $140968 T$ (NR158820)

Penicillium brasilianum CBS 253.55T (MH857470)

Penicillium mariae-crucis CBS 271.83T (MH861585)

Penicillium infrabuccalum DAOMC 250537 (NR172032)

Penicillium pedernalense CBS140770T (NR146250)

Penicillium abidjanum CBS 246.67T (MH858960)

Penicillium daleae CBS 211.28T (MH854984)

Penicillium ubiquetum CBS $126437 T$ (NR121514)

Figure 5. Phylogenetic tree based on ITS sequences showing the relatedness of the Antarctic-derived fungi LAMAI 2400 and LAMAI 2402 and related taxa. Evolutionary distances were calculated using the Maximum Likelihood algorithm and Kimura-2p nucleotide substitution model. Bootstrap values (1000 replicate runs) $>50 \%$ are listed. 
is applicable to select desired organisms by providing them a low-nutrient growth environment to guarantee the specificity for the isolation of effective strains. Enrichment is a valuable tool for isolating microbial consortium by serial inoculations in mineral media with the addition of the pollutant as the sole carbon source (Omrani et al. 2018).

The use of the enrichment strategy for the selective isolation of cold-adapted microorganisms capable of degrading hydrocarbons has been reported in the literature (Pham \& Kim 2012, Wang et al. 2016, Chaudhary \& Kim 2019, Omrani etal. 2018). This process is based on the assumption that hydrocarbons are the only carbon and energy source for the microbial community that can grow under the established conditions. In the study performed by Wang et al. (2016), cold-adapted bacterial strains with great biodegrading potential were isolated. According to Chaudhary \& Kim (2019), this technique could allow a wider evaluation of the yet unexplored psychrophilic population that can be applied in bioremediation processes. Omrani et al. (2018) reported that the fungal consortium submitted to an enrichment process showed a significant potential for degradation, with more pathways during hydrocarbon degradation than bacteria. Additionally, although the use of culture media is a limiting factor to fully know the diversity of microorganisms in the world (Santos et al. 2020), the enrichment strategy can be a useful methodology to reduce this gap, simulating a harsh environment and also discovering new microorganisms with specific properties.

In the present study, a higher number of filamentous fungi was selectively isolated from marine samples in comparison to soil samples, indicating that the fungal diversity from the marine sediment adapted better to the enrichment conditions. Usually, soil samples provide a higher number of isolates in studies conducted without selective pressure. Wentzel et al. (2019) isolated 492 Antarctic filamentous fungi from soil and 24 from marine sediment samples after 7 days of incubation in different culture media at 5 and $15{ }^{\circ} \mathrm{C}$. The low number of isolates recovered in the present study probably occurs because of the restriction of nutrient and carbon sources and to the presence of the dye (pollutant).

\section{Decolorization and detoxification of Sulphur Indigo Blue textile dye}

Among the 11 filamentous fungi selectively isolated from marine and terrestrial Antarctic samples, two (LAMAI 2400 and LAMAI 2402) showed more than $80 \%$ of textile dye decolorization and relatively great biomass production at 15 and $28^{\circ} \mathrm{C}$. Data from molecular and morphological analyses allowed the identification of both fungi as Penicillium cf. oxalicum. The morphological characteristics of both fungi were very similar. Nevertheless, the

Table II. Growth area $\left(\mathrm{cm}^{2}\right)$ of the isolates LAMAI 2400 and LAMAI 2402 in Malt Agar medium at different temperatures. Values indicated by different letters are significantly different according to the ANOVA's test.

\begin{tabular}{|c|c|c|c|c|}
\hline \multirow{2}{*}{ Fungi } & \multicolumn{4}{|c|}{ Area of growth $\left(\mathrm{cm}^{2}\right)$} \\
\hline & $30^{\circ} \mathrm{C}$ & $25^{\circ} \mathrm{C}$ & $20^{\circ} \mathrm{C}$ & $15^{\circ} \mathrm{C}$ \\
\hline LAMAI 2400 & $7.341 \pm 0.248 \mathbf{a}$ & $6.778 \pm 0.673 \mathbf{a}$ & $5.952 \pm 0.303 \mathbf{b}$ & $3.992 \pm 0.074 \mathbf{c}$ \\
\hline LAMAI 2402 & $7.632 \pm 0.353 \mathbf{a}$ & $5.988 \pm 0.356 \mathbf{b}$ & $5.559 \pm 0.290 \mathbf{b}$ & $3.641 \pm 0.45 \mathbf{c}$ \\
\hline
\end{tabular}


ITS sequences of LAMAI 2400 and LAMAI 2402 were a little different. In the study performed by Kubátová et al. (2019), P. oxalicum isolates exhibited a difference of $1.7 \%$ in the ITS region. For accurate taxonomic identification of species from the group of P. oxalicum, additional studies should be performed including analyses of multilgene sequencing (e.g. ITS-LSU, TUB2, RPB2, and $C A M)$, secondary metabolites (extrolites), and other morphological characteristics as reported by Kubátová et al. (2019). Penicillium oxalicum is considered a biotechnologically important species with strains patented as biofertilizers, producers of commercial enzymes, and degraders of pollutants (Kubátová et al. 2019).

The genus Penicillium is spread worldwide, and several species can develop under different and extreme conditions. Although representatives of the genus Penicillium have been frequently isolated from a variety of samples collected in Antarctica (Loque et al. 2010, Gonçalves et al. 2013, Duarte et al. 2018b, Wentzel et al. 2019, Tosi et al. 2010, Godinho et al. 2019, Ogaki et al. 2020, Menezes et al. 2020, Santos et al. 2020), only a few studies have reported the presence of $P$. oxalicum in the Antarctic environments. Ding et al. (2016) reported the recovery of four $P$. oxalicum isolates from soil collected at Fields Peninsula. In the study conducted by Connell \& Staudigel (2013), one clone of $P$. oxalicum was obtained from a dark oligotrophic volcanic ecosystem on Mont Erebus using a culture-independent approach.

Despite their origin, both Penicillium cf. oxalicum strains (LAMAI 2400 and 2402) were classified as mesophilic-psychrotolerant. They grew at all temperatures tested, showing smaller growth areas at $15^{\circ} \mathrm{C}$, with an increase in the growth area when the temperatures were raised. Similar results were reported by Gocheva et al. (2006) in the study performed with two Penicillium specimens, one from the polar region (Antarctica) and the other from a temperate climate. Both fungi were able to grow at temperatures ranging from $12{ }^{\circ} \mathrm{C}$ to $35^{\circ} \mathrm{C}$, and the best growth temperature was between $25^{\circ} \mathrm{C}$ and $30^{\circ} \mathrm{C}$. In the study reported by Marin et al. (1998), spores from the mesophilic P. hordei and $P$. aurantiogriseum were able to germinate and grow at temperatures ranging from $5^{\circ} \mathrm{C}$ to $30^{\circ} \mathrm{C}$ (being $25^{\circ} \mathrm{C}$ the fastest), as well as $37^{\circ} \mathrm{C}$ and 42 ${ }^{\circ} \mathrm{C}$ (more slowly). The majority of the filamentous fungi recovered from samples collected in the Maritime Antarctica are psychrotolerant, and few are psychrophilic (Godinho et al. 2013).

Penicillium cf. oxalicum LAMAI 2400 and LAMAI 2402 were recovered from the same marine sediment sample. In the study performed by Wentzel et al. (2019), fungi from the genus Penicillium were the most abundant in marine sediments. Marine-derived fungi are considered an important microbial resource in the field of textile dye decolorization/degradation, since they are adapted to the high salt and $\mathrm{pH}$ found in marine environments, which are features of textile effluents (Bonugli-Santos et al. 2015).

Bioremediation of colored effluents by fungal cells includes a degradative process and/or biosorption. Enzymatic decolorization/ degradation can be achieved using ligninolytic peroxidase enzymes (e.g., manganese peroxidase, lignin peroxidase and horseradish peroxidase), laccases, azoreductase, among others (Giovanella et al. 2020, vieira et al. 2021). In the case of biosorption, the dye is bound to cellular functional groups and can also accumulate inside the fungal cells (Dzionek et al. 2016, Giovanella et al. 2020). As in degradative processes, biosorption is also considered an efficient, economic and eco-friendly process for industrial wastewater treatment (Singh et al. 2020). 
Fungi from the genus Penicillium have been reported as capable to degrade different classes of synthetic dyes. P. pinophilum decolorized $87 \%$ of malachite green (10 $\mathrm{mg} \mathrm{L}^{-1}$ ) in four days at $28{ }^{\circ} \mathrm{C}$ (Jasińska et al. 2012). In another study, 80-99\% of different azo dyes (100-300 $\mathrm{mg} \mathrm{L}^{-1}$ ) were decolorized by $P$. oxalicum in a process mediated by manganese peroxidase at $30{ }^{\circ} \mathrm{C}$ (Saroj et al. 2014). P. oxalicum has also been reported as able to absorb dyes. In the study performed by Zhang et al. (2003), the mycelial pellet of the fungus P. oxalicum absorbed up to $60 \%$ of the Reactive Blue 19 dye in $10 \mathrm{~min}$, and $91 \%$ in $80 \mathrm{~min}$. In the present study, this phenomenon might have occurred, since the colonies in Malt Broth medium with the addition of Sulphur Indigo Blue textile dye acquired a dark blue color. On the other hand, the higher toxicity found in the bioassays performed with Penicillium cf. oxalicum LAMAI 2400 and LAMAI 2402 in comparison to the control (medium with the textile dye) suggests these fungi transform enzymatically the dye molecule. Microbial degradation can result in the mineralization of the compound or its transformation into less toxic and/or more water-soluble molecules, which can be used as nutrients and consequently, be degraded by other microorganisms (Cerniglia 1997, Cerniglia \& Sutherland 2001). Nevertheless, intermediates of the degradation process of an environmental pollutant can be more toxic than the original compound (Bergsten-Torralba et al. 2009, Giovanella et al. 2020, Vasconcelos et al. 2019). To certify if the color removal of the Sulphur Indigo Blue textile dye by the Antarctic filamentous fungi happened by metabolic pathways, biosorption, or both processes, additional experiments have to be undertaken.

The approach used for fungal isolation from the Antarctic samples allowed the acquisition of microbial resources with the ability to decolorize high rates of Sulphur Indigo Blue dye at 15 and $28^{\circ} \mathrm{C}$, highlighting the potential of the Antarctic fungi Penicillium cf. oxalicum LAMAI 2400 and LAMAI 2402 for textile dye bioremediation in processes conducted at low and moderate temperatures. Considering the biotechnological relevance of the fungus $P$. oxilacum, as well as the fact that representatives of this species have rarely been reported in Antarctic environments, the two selected filamentous fungi recovered from Antarctic marine sediments added value to the UNESP Microbial Culture Collection (CRM-UNESP) and will be available for further studies related to Antarctic mycology and biotechnological application in industrial and environmental microbiology. Additionally, the lack of information about representatives of this fungal species in the field of textile dye bioremediation opens new perspectives for studies related to pathways and genes involved in the degradative process.

\section{Acknowledgments}

This research was supported by Fundação de Amparo à Pesquisa do Estado de São Paulo (FAPESP) (grant \#2018/12098-9) and Conselho Nacional de Desenvolvimento Científico e Tecnológico (CNPq) (grant \#407986/2018-6). DMK thanks FAPESP for the Scientific Initiation scholarship (\#2019/01632-7), TTY thanks CNPq (\#130461/2019-9) for the Master scholarship. PG thanks FAPESP for the Postdoctoral Fellowship (\#2016/174884), EPP thanks CNPq (\#130364/2017-7) for the Master scholarship. LDS thanks CNPq for the Productivity Fellowship (303218/2019-3). The authors thank the MICROSFERA project (PROANTAR/CNPq) for the support with sample collection, lago Duarte for contributing with map preparation, and Milene Ferro for the help with phylogenetic tree generation.

\section{REFERENCES}

ABRAMOFF MD, MAGALHÃES PJ \& RAM SJ. 2004. Image processing with Image. J Biophotonics Int 11: 36-42.

ALTSCHUL SF, GISH W, MILLER W, MYERS EW \& LIPMAN DJ. 1990. Basic local alignment search tool. J Mol Biol 215: 403-410. 
AMEEN F, MOSLEM M, HADI S \& AL-SABRI AE. 2016. Biodegradation of diesel fuel hydrocarbons by mangrove fungi from Red Sea Coast of Saudi Arabia. Saudi J Biol Sci 23: 211-218.

BERGSTEN-TORRALBA LR, NISHIKAWA MM, BAPTISTA DF, MAGALHÃES DP \& SILVA M. 2009. Decolorization of different textile dyes by Penicillium simplicissimum and toxicity evaluation after fungal treatment. Braz J Microbiol 40: 808-817.

BONUGLI-SANTOS RC, DURRANT LR \& SETTE LD. 2012. The production of ligninolytic enzymes by marine-derived basidiomycetes and their biotechnological potential in the biodegradation of recalcitrant pollutants and the treatment of textile effluents. Water Air Soil Poll 223: 2333-2345.

BONUGLI-SANTOS RC ET AL. 2015. Marine-derived fungi: diversity of enzymes and biotechnological applications. Front Microbiol 6: 1-15.

CERNIGLIA CE. 1997. Fungal metabolism of polycyclic aromatic hydrocarbons: past, present and future applications in bioremediation. J Ind Microbiol Biot 19: 324-333.

CERNIGLIA CE \& SUTHERLAND JB. 2001. Bioremediation of Polycyclic Aromatic Hydrocarbons by Ligninolytic and Non-Ligninolytic Fungi. In: Gadd GM (Ed), Fungi In Bioremediation (British Mycological Society), Cambridge: Cambridge University Press, Cambridge, United Kingdon, p. 136-187.

CHAUDHARY DK \& KIM J. 2019. New insights into bioremediation strategies for oil-contaminated soil in cold environments. Int Biodeter Biodegr 142: 58-72.

CHAUHAN AK \& CHOUDHURY B. 2021. Synthetic dyes degradation using lignolytic enzymes produced from Halopiger aswanensis strain ABC_IITR by Solid State Fermentation. Chemosphere 273: 129671.

CHEQUER FMD, DORTA DJ \& OLIVEIRA DP. 2011. Azo Dyes and Their Metabolites: Does the Discharge of the Azo Dye into Water Bodies Represent Human and Ecological Risks? In: Advances In: Hauser PJ (Ed), Treating Textile Effluent, [S.I.]: Open Access Library, [S.I.], p. 27-48.

CHUNG KT, STEVENS SE \& CERNIGLIA CE. 1992. The Reduction of Azo Dyes by the Intestinal Microflora. Crit Rev Microbiol 18: $175-190$.

CONNELL L \& STAUDIGEL H. 2013. Fungal Diversity in a Dark Oligotrophic Volcanic Ecosystem (DOVE) on Mount Erebus, Antarctica. Biology 2: 798-809.
DING Z, LI L, CHE Q, LI D, GU Q \& ZHU T. 2016. Richness and bioactivity of culturable soil fungi from the Fildes Peninsula, Antarctica. Extremophiles 20: 425-435.

D'ELIA T, VEERAPANENI R, THERAISNATHAN $V$ \& ROGERS SO. 2009. Isolation of fungi from Lake Vostok accretion ice. Mycologia 101: 751-763.

DUARTE AWF ET AL. 2018a. Cold-adapted enzymes produced by fungi from terrestrial and marine Antarctic environments. Crit Rev Biotechnol 38: 600-619.

DUARTE AWF ET AL. 2018b. Production of cold-adapted enzymes by filamentous fungi from King George Island, Antarctica. Polar Biol 41: 2511-2521.

DZIONEKA, WOJCIESZYŃSKA D \& GUZIK U. 2016. Natural carriers in bioremediation: a review. Electron J Biotechnol 23: 28-36.

EDGAR RC. 2004. MUSCLE: multiple sequence alignment with high accuracy and high throughput. Nucleic Acids Res 32(5): 1792-1797.

ENAYATZAMIR K, TABANDEH F, YAKHCHALI B, ALIKHANI HA \& COUTO SR. 2009. Assessment of the joint effect of laccase and cellobiose dehydrogenase on the decolouration of different synthetic dyes. J Hazard Mater 169: 176-181.

GIOVANELLA P, VIEIRA GAL, OTERO IVR, PELLIZZER EP, FONTES BJ \& SETTE LD. 2020. Metal and organic pollutants bioremediation by extremophile microorganisms. J Hazard Mater 382: 1-45.

GOCHEVA YG ET AL. 2006. Cell response of Antarctic and temperate strains of Penicillium spp. to different growth temperature. Mycol Res 110: 1347-1354.

GODINHO VM ET AL. 2013. Diversity and bioprospecting of fungal communities associated with endemic and coldadapted macroalgae in Antarctica. ISME J 7: 1434-1451.

GODINHO VM ET AL. 2019. Diversity and distribution of hidden cultivable fungi associated with marine animals of Antarctica. Fungal Biol 123: 507-516.

GONÇALVES VN ET AL. 2013. Penicillium solitum: A mesophilic, psychrotolerant fungus present in marine sediments from Antarctica. Polar Biol 36: 1823-1831.

HALL TA. 1999. BioEdit: a user-friendly biological sequence alignment editor and analysis program for windows 95/98/NT. Nucleic Acids Symp Ser 41: 95-98.

HOSSAIN L, SARKER SK \& KHAN MS. 2018. Evaluation of Present and Future Wastewater Impacts of Textile Dyeing Industries in Bangladesh. Environ Dev 26: 23-33.

HUANG X \& MADAN A. 1999. CAP3: A DNA sequence assembly program. Genome Res 9: 868-877. 
JASIŃSKA A ET AL. 2012. Malachite green decolorization by non-basidiomycete filamentous fungi of Penicillium pinophilum and Myrothecium roridum. Int Biodeter Biodegr 73: 33-40.

KIMURA M. 1980. A simple method for estimating evolutionary rates of base substitutions through comparative studies of nucleotide sequence. J Mol Evol 16: 111-120.

KRISHNAN P. 2011. High-Temperature Effects on Rice Growth, Yield, and Grain Quality. Adv Agron 111: 87-206.

KUBÁTOVÁ A, HUJSLOVÁ M, FRISVAD JC, CHUDÍČKOV M \& KOLAŘÍK M. 2019. Taxonomic revision of the biotechnologically important species Penicillium oxalicum with the description of two new species from acidic and saline soils. Mycol Progress 18: 215-228.

KUMAR S, STECHER G, LI M, KNYAZ C \& TAMURA K. 2018. MEGA $X$ : Molecular Evolutionary Genetics Analysis across computing platforms. Mol Biol Evol 35: 1547-1549.

LACERDA LT, GUSMÃO LFP \& RODRIGUES A. 2018. Diversity of endophytic fungi in Eucalyptus microcorys assessed by complementary isolation methods. Mycol Prog 17: 1-9.

LETUNIC I \& BORK P. 2021. Interactive Tree of Life (iTOL) v5: an online tool for phylogenetic tree display and annotation, Nucleic Acids Res 49(W1): W293-W296.

LOQUE CP ET AL. 2010. Fungal community associated with marine macroalgae from Antarctica. Polar Biol 33: 641-648.

MARGESIN R, FELLER G, GERDAY C \& RUSSELL N. 2002. Coldadapted microorganisms: adaptation strategies and biotechnological potential. In: Bitton G (Ed), The encyclopedia of environmental microbiology, New York: J Wiley \& Sons, New York, USA, p. 871-885.

MARÍN S ET AL. 1998. Ecological determinants for germination and growth of some Aspergillus and Penicillium spp. from maize grain. J Appl Microbiol 84: 25-36.

MENEZES GCA ET AL. 2020. Fungi in glacial ice of Antarctica: diversity, distribution and bioprospecting of bioactive compounds. Extremophiles 24: 367-376.

MOSTAFA AA, ELSHIKH MS, AL-ASKAR AA, HADIBARATA T, YUNIARTO A \& SYAFIUDDIN A. 2019. Decolorization and biotransformation pathway of textile dye by Cylindrocephalum aurelium. Biop Biosyst Eng 42: 1483-1494.

OGAKI MB ET AL. 2020. Diversity and bioprospecting of cultivable fungal assemblages in sediments of lakes in the Antarctic Peninsula. Fungal Biol 124: 601-611.
OMRANI R, SPINI G, PUGLISI E \& SAIDANE D. 2018. Modulation of microbial consortia enriched from different polluted environments during petroleum biodegradation. Biodegradation 29: 187-209.

ONOFRI S, SELBMANN L, HOOG GS, GRUBE M, BARRECA D, RUISI S \& ZUCCONI L. 2007. Evolution and adaptation of fungi at boundaries of life. Adv Space Res 40: 1657-1664.

ORTIZ-MONSALVE S, VALENTE P, POLL E, JARAMILLO-GARCÍA V, PEGAS HENRIQUESJA \& GUTTERRES M.2019. Biodecolourization and biodetoxification of dye-containing wastewaters from leather dyeing by the native fungal strain Trametes villosa SCS-10. Biochem Eng J 141: 19-28.

PESCIAROLI C, CUPINI F, SELBMANN L \& BARGHINI P. 2012. Temperature preferences of bacteria isolated from seawater collected in Kandalaksha Bay, While Sea, Russia. Polar Biol 35: 435-445.

PHAM VHT \& KIM J. 2012. Cultivation of unculturable soil bacteria. Trends Biotechnol 30: 475-484.

PRAMANIK S \& CHAUDHURI S. 2018. Laccase activity and azo dye decolorization potential of Podoscypha elegans. Mycobiology 46: 79-83.

RUISI S, BARRECA D, SELBMANN L, ZUCCONI L \& ONOFRI S. 2007. Fungi in Antarctica. Rev Environ Sci Bio 6: 127-141.

SANTOS JA, MEYER E \& SETTE LD. 2020. Fungal community in antarctic soil along the retreating collins glacier (Fildes peninsula, King George Island). Microorganisms 8: 1-15.

SAROJ S ET AL. 2014. Biodegradation of azo dyes Acid Red 183, Direct Blue 15 and Direct Red 75 by the isolate Penicillium oxalicum SAR-3. Chemosphere 107: 240-248.

SELBMANN L. 2019. Extreme-fungi and the benefits of a stressing life. Life 9: 31.

SEN SK, RAUT SMITA, BANDYOPADHYAY P \& RAUT S. 2016. Fungal decolouration and degradation of azo dyes: A review. Fungal Biol Rev 30: 112-133.

SINGH S, KUMAR V, DATTA S, DHANJAL DS, SHARMA K, SAMUEL I \& SINGH J. 2020. Current advancement and future prospect of biosorbents for bioremediation. Sci Total Environ 709: 135895.

SPINI G, SPINA F, POLI A, BLIEUX AL, REGNIER T, GRAMELLINI C, VARESE GC \& PUGLISI E. 2018. Molecular and Microbiological Insights on the Enrichment Procedures for the Isolation of Petroleum Degrading Bacteria and Fungi. Front Microbiol 9.

TOSI S ET AL. 2010. Antioxidant enzyme activity of filamentous fungi isolated from Livingston Island, maritime Antarctica. Polar Biol 33: 1227-1237. 
VARRELLA S, BARONE G, TANGHERLINI M, RASTELLI E, DELL'ANNO A \& CORINALDESI C. 2021. Diversity, Ecological Role and Biotechnological Potential of Antarctic Marine Fungi. J Fungi 7: 391.

VASCONCELOS MRS, VIEIRA GAL, OTERO IVR, BONUGLI-SANTOS RC, RODRIGUES MVN, REHDER VLG, FERRO M, BOAVENTURA S, BACCI M \& SETTE LD. 2019. Pyrene degradation by marinederived ascomycete: process optimization, toxicity, and metabolic analyses. Environ Sci Pollut R 26: 12412-12424.

VIEIRA GAL, CABRAL L, OTERO IVR, FERRO M, FARIA AU, OLIVEIRA VM, BACCI M \& SETTE LD. 2021. Marine associated microbial consortium applied to RBBR textile dye detoxification and decolorization: combined approach and metatranscriptomic analysis. Chemosphere 267: 1-12.

WANG J ET AL. 2016. Cold-adapted bacteria for bioremediation of crude oil-contaminated soil. J Chem Technol Biot 91: 2286-2297.

WANG X ET AL. 2001. Validation of germination rate and root elongation as indicator to assess phytotoxicity with Cucumis sativus. Chemosphere 44: 1711-1721.

WENTZEL LCP ET AL. 2019. Fungi from Admiralty Bay (King George Island, Antarctica) Soils and Marine Sediments. Microb Ecol 77: 12-24.

WILKINS D, YAU S, WILLIAMS TJ, ALLEN MA, BROWN MV, DEMAERE MZ, LAURO FM \& CAVICCHIOLI R. 2013. Key microbial drivers in Antarctic aquatic environments. Fems Microbiol Rev 37: 303-335.

WYNN-WILLIAMS DD. 1996. Antarctic microbial diversity: the basis of polar ecosystem processes. Biodivers Conserv 5: 1271-1293.

YERGEAU E \& KOWALCHUK GA. 2008. Responses of Antarctic soil microbial communities and associated functions to temperature and freeze-thaw cycle frequency. Environ Microbiol 10: 2223-2235.

ZHANG SJ, YANG M, YANG QX, ZHANG Y, XIN BP \& PAN F. 2003. Biosorption of Reactive Dyes by the Mycelium Pellets of a New Isolate of Penicillium oxalicum. Biotech Let 25: 1479-1482.

\section{How to cite}

KITA DM, GIOVANELLA P, YOSHINAGA TT, PELLIZZER EP \& SETTE LD. 2022. Antarctic fungi applied to textile dye bioremediation. An Acad Bras Cienc 94: e20210234. DOI 10.1590/0001-3765202220210234.
Manuscript received on February 14, 2021;

accepted for publication on July 13, 2021

DANIELA M. KITA ${ }^{1}$

https://orcid.org/0000-0001-8733-6479

PATRICIA GIOVANELLA, ${ }^{1,2}$

https://orcid.org/0000-0002-1207-4459

THAÍS T. YOSHINAGA 1

https://orcid.org/0000-0002-0601-7650

\section{ELISA P. PELLIZZER}

https://orcid.org/0000-0002-1936-6331

\section{LARA D. SETTE ${ }^{1,2}$}

https://orcid.org/0000-0002-5980-3786

${ }^{1}$ Departamento de Biologia Geral e Aplicada, Instituto de Biociências, Universidade Estadual Paulista Júlio de Mesquita Filho (UNESP), Av. 24A, 1515, 13506-900 Rio Claro, SP, Brazil

${ }^{2}$ Centro de Estudos Ambientais, Instituto de Biociências, Universidade Estadual Paulista Júlio de Mesquita Filho (UNESP), Av. 24A, 1515, 13506-900 Rio Claro, SP, Brazil

Correspondence to: Lara D. Sette

E-mail: lara.sette@unesp.br

\section{Author contributions}

DMK: Experimental analyses, Original draft preparation; TTY: Fungal identification and classification, Figure Editing, Reviewing; PG: Conceptualization, Co-supervision, Figure Editing, Reviewing; EPP: collection of Antarctic samples, Figure editing, Reviewing; LDS: Conceptualization, Supervision, Reviewing, Editing, and Funding acquisition.

\section{(cc) BY}

